\title{
Cellulase recycling after high-solids simultaneous saccharification and fermentation of combined pretreated corncob
}

\author{
Ruoyu Du ${ }^{1}$, Rongxin Su ${ }^{1,2,3}{ }^{*}$, Mingjia Zhang ${ }^{1}$, Wei $\mathrm{Qi}^{1,2,3}$ and Zhimin $\mathrm{He}^{1}$ \\ 1 State Key Laboratory of Chemical Engineering, School of Chemical Engineering and Technology, Tianjin University, Tianjin, China \\ ${ }^{2}$ Collaborative Innovation Center of Chemical Science and Engineering, Tianjin, China \\ ${ }^{3}$ Tianjin Key Laboratory of Membrane Science and Desalination Technology, Tianjin University, Tianjin, China
}

\section{Edited by:}

Soo-Jeong Shin, Chungbuk National

University, South Korea

Reviewed by:

Yu-Shen Cheng, University of

California Davis, USA

Soo-Jeong Shin, Chungbuk National

University, South Korea

*Correspondence:

Rongxin Su, State Key Laboratory of

Chemical Engineering, School of

Chemical Engineering and

Technology, Tianjin University, Tianjin

300072, China

e-mail:surx@tju.edu.cn
Despite the advantageous prospect of second-generation bioethanol, its final commercialization must overcome the primary cost impediment due to enzyme assumption. To solve this problem, this work achieves high-concentration ethanol fermentation and multi-round cellulase recycling through process integration. The optimal time and temperature of the re-adsorption process were determined by monitoring the adsorption kinetics of cellulases. Both glucose and cellobiose inhibited cellulase adsorption. After $96 \mathrm{~h}$ of ethanol fermentation, $40 \%$ of the initial cellulase remained in the broth, from which $62.5 \%$ of the cellulase can be recycled and reused in fresh substrate re-adsorption for $90 \mathrm{~min}$. Under optimum conditions, i.e., pH 5.0, dry matter loading of $15 \mathrm{wt} \%$, cellulase loading of $45 \mathrm{FPU} / \mathrm{g}$ glucan, two cycles of fermentation and re-adsorption can yield twofold increased ethanol outputs and reduce enzyme costs by over $50 \%$. The ethanol concentration in each cycle can be achieved at levels $>40 \mathrm{~g} / \mathrm{L}$.

Keywords: cellulase, lignocellulose, enzyme recycling, high-solids, simultaneous saccharification and fermentation

\section{INTRODUCTION}

Second-generation bioethanol produced from lignocellulosic materials presents a good potential alternative to - exhaustible fossil fuels because of its renewability, low environmental impact, and limited employment of food crops (Huang et al., 2011). Since corncob has a wide distribution and high bulk density for bioethanol production, its collection and transport are highly convenient (Liu et al., 2010). Considering these advantages, several energy companies, such as POET, DDCE, and ABENGOA, have chosen corncob as a major feedstock for bioethanol production. Unfortunately, the full commercial deployment of bioethanol bioconversion is challenged by two major obstacles: the high cost of enzymes (Tu et al., 2009) and the recalcitrant block of non-cellulosics (mainly hemicellulose and lignin) (Zhang et al., 2010b).

To remove recalcitrant blocks, several methods for corncob pretreatment have been applied, including use of dilute acid (Wang et al., 2011), use of formic acid (Huang et al., 2010a), and soaking in aqueous ammonia (Huang et al., 2010b). We previously evaluated a combined pretreatment with dilute sulfuric acid-sodium hydroxide (Zhang et al., 2010b) to increase the relative amount of cellulose and improve the digestibility of corncob during high-solids ethanol fermentation. Although efforts from many researchers and enzyme companies have focused on increasing the production efficiency and specific activity of enzymes, enzyme recycling and reuse is a more practical strategy to reduce enzyme cost (Huang et al., 2011). Several recycling strategies, such as $\beta$-glucosidase immobilization (Tu et al., 2006; Wang et al., 2009), enzyme ultrafiltration (Qi et al., 2011, 2012), and enzyme re-adsorption (Tu and Saddler, 2010), have been applied in lignocellulosic hydrolysis.
During lignocellulosic hydrolysis, cellulases can either remain bound to the solid residues or freely suspend in the liquid phase (Du et al., 2012). Because of their relatively high stability and natural affinity to cellulose, these free proteins can be recycled by re-adsorption onto the fresh substrate. Tu et al. (2007b) successfully recycled free cellulase in hydrolyzates by addition of fresh pretreated lodgepole after hydrolysis. These experiments, however, were performed at a low cellulose consistency $(2 \%)$, which cannot facilitate high-concentration ethanol production. Moreover, cellulase recycling was performed after the hydrolysis part of separate hydrolysis and fermentation (SHF), which is disadvantageous for high-solids saccharification because certain hydrolysis products, such as glucose and particularly cellobiose, inhibit cellulase adsorption (Kristensen et al., 2009b).

Simultaneous saccharification and fermentation (SSF) has been proven to be a promising alternative to SHF for commercial bioethanol production (Li et al., 2009). In SSF, inhibition of cellulase by the end-product is minimized because glucose and cellobiose are consumed in situ by the fermenting microorganism, such as Saccharomyces cerevisiae (Tomás-Pejó et al., 2008; Zhang et al., 2009). Another advantage of SSF is that the process is integrated in one reactor, thereby reducing equipment costs and decreasing the probability of contamination (Georgieva et al., 2008). Furthermore, SSF conducting at highsolids is highly required in practical ethanol production (solid content $>15 \%$ ), which is benefit to reduce the moisture content of the fermentation system and to increase the final ethanol concentration facilitating the subsequent distillation (Kristensen et al., 2009b). 
The present study aims to: (1) study the feasibility of cellulase recycling strategy in which high-solid SSF is integrated with enzyme re-adsorption; and (2) optimize the operating parameters of this strategy and evaluate the cost savings of enzyme recycling in practical operation using the proposed method.

\section{MATERIALS AND METHODS LIGNOCELLULOSIC SUBSTRATES}

Corncob (glucan, 35.9\%; xylan, 32.7\%; lignin, 18.8\%) was obtained from a local farm (Tianjin, China), pre-milled, air-dried, and screened thought 20-40 meshes. All corncob samples were pretreated according to the method described as "combined pretreatment" by Zhang et al. (2010b). The corncobs were incubated in an autoclave with $2 \mathrm{wt} \% \mathrm{H}_{2} \mathrm{SO}_{4}(6: 1 \mathrm{liquid} /$ solid ratio $)$ at $121^{\circ} \mathrm{C}$ for $1 \mathrm{~h}$. After reaction, the corncob residues were filtered, washed with water to neutral $\mathrm{pH}$, extruded until no water drop, and then soaked in $15 \mathrm{wt} \%$ aqueous ammonia (6:1 liquid/solid ratio) at $60^{\circ} \mathrm{C}$ for $12 \mathrm{~h}$. Finally, the pretreated corncobs were separated from the black liquor, washed, oven-dried overnight, and stored at $4^{\circ} \mathrm{C}$ for subsequent experiments. The dry weight composition of these samples was $77.5 \%$ cellulose, $11.6 \%$ hemicellulose, and 7.0\% lignin.

\section{ENZYME AND YEAST}

Cellulase (GC220, $160 \mathrm{FPU} / \mathrm{mL}$ ) was purchased from Genencor International (Palo Alto, CA, USA). The $\beta$-glucosidase preparation (Novozyme 188, 926 CBU/mL) was purchased from Sigma (St. Louis, MO, USA). Commercial ethanol instant active dry yeast (S. cerevisiae) was obtained from Angel Yeast Co., Ltd., Wuhan, China.

\section{ANALYSIS}

The components of the raw and pretreated corncobs, as well as those of the fermentation residues, were determined by the NREL procedure LAP-002. Soluble sugars and ethanol in the liquid samples were assayed by high-performance liquid chromatography (HPLC) using an Aminex HPX-87H column (Bio-Rad, Hercules, CA, USA) at $65^{\circ} \mathrm{C}$ using $50 \mathrm{mM} \mathrm{H}_{2} \mathrm{SO}_{4}$ as the mobile phase at a flow rate of $0.6 \mathrm{~mL} / \mathrm{min}$. The filter paper unit (FPU) of cellulase was measured according to a standard method (Ghose, 1987). Cellulase concentrations were determined following the Bradford method (Bradford, 1976). Single cellulases of the culture supernatants were purified by SDS-PAGE according to the literature (Laemmli, 1970) using acrylamide gels (10\%) and a Bio-Rad Mini-protean 3 electrophoresis cell.

\section{LIGNOCELLULOSIC HYDROLYSIS AND CELLULASE ADSORPTION}

Combined pretreated corncob (CPC) was preheated in citric acid buffer ( $50 \mathrm{mM}, \mathrm{pH} 5.0$, up to $5 \mathrm{~g} / 50 \mathrm{~mL}$ reaction mixture) at $50^{\circ} \mathrm{C}$ with shaking for $10 \mathrm{~min}$. Cellulase (GC 220) was then added to initiate hydrolysis for $48 \mathrm{~h}$. In each sampling, $1 \mathrm{~mL}$ aliquots were obtained from the mixture suspensions and centrifuged at $5,000 \mathrm{rpm}$ for $4 \mathrm{~min}$. Unbound proteins and soluble sugars of these samples were determined using methods described in the previous section. Adsorbed proteins were calculated from the difference between unbound and added proteins.

To study the factors influencing cellulase adsorption during actual hydrolysis and re-adsorption, the reaction temperature, reaction time, and sugar concentration in the hydrolyzates were investigated. CPC samples were incubated in citric acid buffer (50 mM, pH 5.0, DM 10\%) with (i) the same GC220 loading (30 FPU/g cellulose) at different temperatures or (ii) with different glucose or cellobiose concentrations at a constant temperature of $20^{\circ} \mathrm{C}$.

\section{SSF AND ENZYME RECYCLING}

For SSF batch experiments, the CPC slurry was diluted with citrate buffer $(50 \mathrm{mM}, \mathrm{pH} 4.5-5.5)$ in a $250 \mathrm{~mL}$ shake flask to obtain the desired initial DM concentration $(12-18 \%$, w/v). The SSF medium was supplemented with the following: $\left(\mathrm{NH}_{4}\right)_{2} \mathrm{HPO}_{4}$, $0.5 \mathrm{~g} / \mathrm{L} ; \mathrm{MgSO}_{4} \cdot 7 \mathrm{H}_{2} \mathrm{O}, 0.025 \mathrm{~g} / \mathrm{L}$; and yeast extract, $1.0 \mathrm{~g} / \mathrm{L}$. CPC digestion was initiated by addition of the cellulase cocktail (GC220, 15-45 FPU; Novozyme 188, 20 CBU) and prehydrolysis for $24 \mathrm{~h}$ at $50^{\circ} \mathrm{C}$. Afterward, dry yeast was added $(2 \mathrm{~g} / \mathrm{L})$ to the mixture to perform SSF for $96 \mathrm{~h}$ as soon as the reaction temperature decreased to $30^{\circ} \mathrm{C}$ (Figure 1). During prehydrolysis, SSF, and re-adsorption, the kinetics of cellulase adsorption were determined by quantifying the protein content in the supernatant; the distributions of these enzymes were also characterized by SDS-PAGE assay. After SSF, the solid residue was washed, dried, and weighed, and its chemical components were analyzed. The analytical procedures were performed according to the methods described in the previous section. The SSF conditions (i.e., DM concentration, cellulase loading, and $\mathrm{pH}$ ) are listed in Table $\mathbf{1 .}$

Experiments for cellulase recycling were operated according to the designed scheme (Figure 1), which integrates the SSF process and enzyme re-adsorption. After $96 \mathrm{~h}$ of SSF, the solids were filtered using a glass microfiber membrane (Whatman GF/A) and the liquid was mixed with fresh substrate with the same uptake as the first cycle of SSF to reabsorb the free cellulase in the filtrate. After $90 \mathrm{~min}$ of re-adsorption at $20^{\circ} \mathrm{C}$, the enzyme bound to the substrate was refiltered and resuspended in the culture fluid. Thereafter, fresh Novozyme 188 (20 CBU) was added to the mixture and a second cycle of SSF was initiated. The refiltrate was collected to determine ethanol and sugar concentrations.

Cellulose conversion and ethanol yield were calculated according to a previous study (Varga et al., 2004). Activity recovery (AR) of cellulase and productivity recovery (PR) of ethanol were defined and calculated according to the following equation:

$$
\begin{aligned}
& \text { Activity recovery (\%) } \\
& =\frac{\sum \text { Cellulose conversion in } n(n>1) \text { round SSF }(\%)}{\text { Cellulose conversion in } 1 \text { st SSF }(\%)} \times 100
\end{aligned}
$$

Productivity recovery (\%)

$$
=\frac{\sum C_{\text {Ethanol }}\left(\mathrm{g} \cdot \mathrm{L}^{-1}\right) \text { in } n(n>1) \text { round SSF }(\%)}{C_{\text {Ethanol }}\left(\mathrm{g} \cdot \mathrm{L}^{-1}\right) \text { in } 1 \text { st SSF }(\%)} \times 100 .
$$

\section{RESULTS AND DISCUSSION CHARACTERIZATION OF RAW MATERIAL}

The chemical compositions of corncob and pretreated corncob are shown in Table 2 . Hemicellulose and lignin contents respectively 


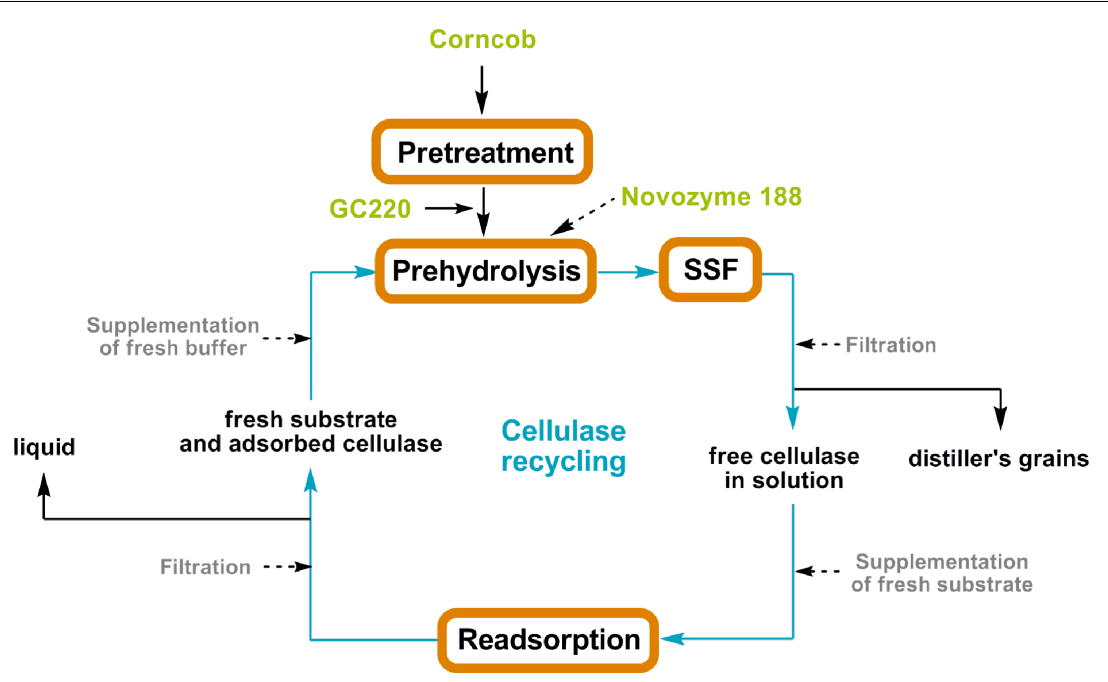

FIGURE 1 | Enzyme recycling strategy integrating cellulase re-adsorption with the SSF process.

Table 1 | Operating parameters (DM, cellulase loading, and $\mathrm{pH}$ ) for the SSF experiments.

\begin{tabular}{lccc}
\hline $\begin{array}{l}\text { Experiment } \\
\text { No. }\end{array}$ & DM (\%) & $\begin{array}{l}\text { GC220 loading } \\
\text { (FPU/g cellulose) }\end{array}$ & pH \\
\hline 1 & & 30 & 5.0 \\
2 & 12 & 15 & 5.0 \\
3 & 15 & 30 & 4.5 \\
4 & 15 & 30 & 5.0 \\
5 & 15 & 30 & 5.5 \\
6 & 15 & 45 & 5.0 \\
7 & 15 & 30 & 5.0 \\
\hline
\end{tabular}

Table 2 | Chemical compositions of corncob before and after combined pretreatment.

\begin{tabular}{lcccc}
\hline Substrate & Glucan & Xylan & Klason lignin & ASL $^{\mathbf{a}}$ \\
\hline Corncob & 35.9 & 32.7 & 16.5 & 2.28 \\
Pretreated corncob & 77.5 & 11.6 & 6.3 & 0.66 \\
\hline
\end{tabular}

${ }^{a} A S L$, acid soluble lignin.

decreased to 11.6 and $7.0 \%$, which indicates that most of these two fractions are degraded or solubilized by dilute sulfuric acid and aqueous ammonia. Lignin has been reported to adsorb cellulase by lignin-enzyme interactions, resulting in non-productive binding (Berlin et al., 2005). Thus, the low lignin content of the pretreated substrate could help reduce the non-productive binding of cellulase during SSF (Du et al., 2012) and subsequently facilitate enzyme re-adsorption and recycling of enzyme. Cellulose contents increased from 35.9 to $77.5 \%$ with the removal of hemicellulose and lignin. During SSF, high cellulose contents of the feedstock are vital for: (i) obtaining high fermentable sugar and ethanol concentrations (Jørgensen et al., 2007) and (ii) promoting SSF

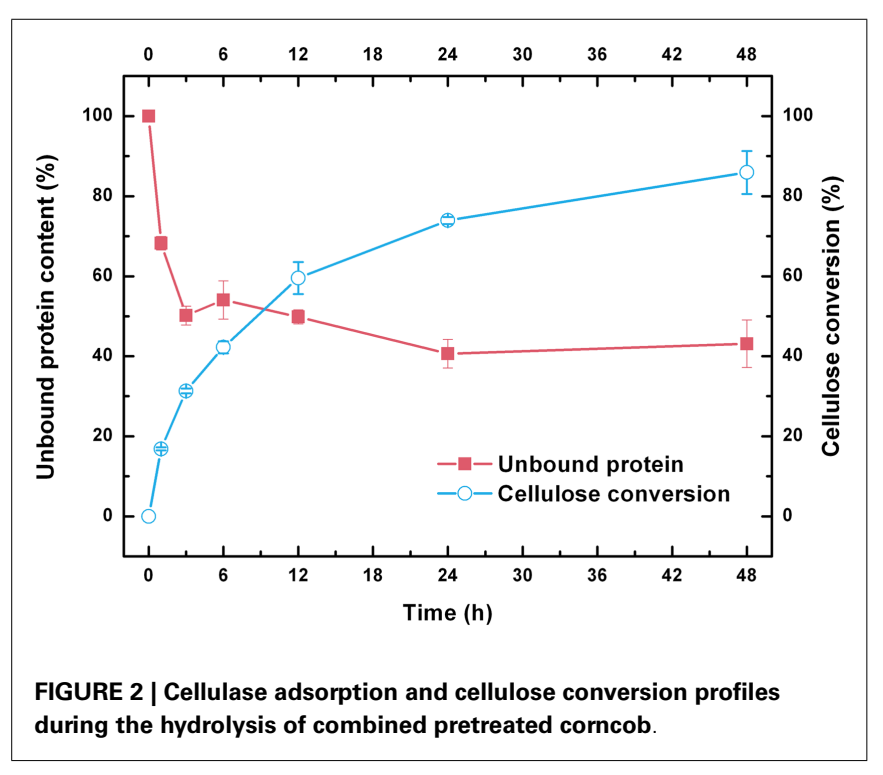

operation under high-solid contents by increasing substrate density and decreasing slurry viscosity via removal of non-cellulosic fractions (Zhang et al., 2010b).

\section{CELLULASE ADSORPTION AND DESORPTION}

Unlike classical enzyme kinetics, biodegradation of insoluble cellulose must be tracked synchronously during cellulase adsorption and glucose release because of the heterogeneous nature of the reaction (Bansal et al., 2009). As shown in Figure 2, 50\% of the initial total cellulase was rapidly bound to the $\mathrm{CPC}$ within $3 \mathrm{~h}$ of hydrolysis. After $3 \mathrm{~h}$ of hydrolysis, the bound cellulase increased slowly, and the amount of bound enzymes at $24 \mathrm{~h}$ was only $10 \%$ more than that observed at $3 \mathrm{~h}$. Thereafter, bound cellulases were desorbed from the CPC, which may be attributed to gradual degradation of the substrate into oligo- and monosaccharides (Du et al., 
2013). After 48 h of hydrolysis, $86 \%$ of the insoluble cellulose component in the substrate was converted to soluble glucose. However, a considerable amount of cellulase ( $>50 \%$ ) remained adsorbed on the solid residues. The bound cellulases at this point were mainly adsorbed on the lignin because most of the cellulose fraction in the substrate is hydrolyzed (Du et al., 2013).

To optimize the operating temperature and time for readsorption, the adsorption kinetics of cellulase under different temperature were measured (Figure 3A). When the equilibrium time was held constant at $90 \mathrm{~min}$, the adsorption rates and equilibrium values of cellulase increased with increasing temperature. About 60 and $70 \%$ of the initial cellulase was bound to the substrate when adsorption reached equilibrium at 20 and $50^{\circ} \mathrm{C}$, respectively. Previous studies have reported that the optimum temperature of Trichoderma reesei cellulase is $50^{\circ} \mathrm{C}$ (Lynd et al., 2002), and $<3 \%$ of the substrate is digested by this cellulase at $25^{\circ} \mathrm{C}$ for $1 \mathrm{~h}$ (Tu et al., 2007a). Based on these results, we selected $20^{\circ} \mathrm{C}$ (ambient temperature) as the operating temperature and $90 \mathrm{~min}$ as the operating time for the re-adsorption process.

Glucose and cellobiose have been reported to cause significant inhibition of cellulase activity (Zheng et al., 2009; Andric et al., 2010). To determine whether or not these sugars affect cellulase adsorption, a certain amount of glucose or cellobiose was added into the buffer prior to introduction of the cellulase to the lignocellulosic substrate. The glucose or cellobiose dosage was selected according to the content in the hydrolyzate to produce an environment as similar to actual practices as possible. As shown in Figure 3B, both glucose and cellobiose exert inhibitory effects on cellulase adsorption, and this effect became stronger with the increase in sugar concentration. When the glucose concentration increased from 0 to $2 \mathrm{mg} / \mathrm{mL}$, the cellulase which adsorbs onto the solid substrate decreased from 46 to $36 \%$. Approximately $37 \%$ of cellulase adsorbed on the substrate while the cellobiose concentration was only $0.2 \mathrm{mg} / \mathrm{mL}$. Compared with glucose, inhibition of cellobiose was more evident. When the cellobiose concentration was increased to $1.6 \mathrm{~g} / \mathrm{L}$, only $26 \%$ of the cellulase was adsorbed onto the solid substrate, showing a $44.7 \%$ decrease. When enzyme hydrolysis was operated at high DM, both the glucose and cellobiose were accumulated. The high concentration of these inhibitors affected digestion and adsorption, which means SHF is not suitable for high-solid reactions and cellulase recycling. To eliminate these inhibitory effects, cellulase re-adsorption combined with SSF was performed.

\section{ENZYME RECYCLING AND SSF PROCESS}

To evaluate the feasibility of the recycling strategy illustrated in Figure 1, the protein content in the liquid phase was monitored, and the cellulase distribution between the solid and liquid phases was determined. Figure $\mathbf{4 A}$ shows the change in free protein concentration in the solution during prehydrolysis, SSF, and re-adsorption. After $1 \mathrm{~h}$ of prehydrolysis, $\sim 70 \%$ of the cellulases were adsorbed onto the corncob substrate. However, these enzymes began to return to their free state thereafter. After $96 \mathrm{~h}$ of SSF, $\sim 40.6 \%$ of the total protein was free in the liquid phase, of which over $10 \%$ desorbed from solid substrate. About $60 \%$ of the cellulase remained bound to the solid residues and could not be recovered. In a previous report, $\sim 51 \%$ of the added cellulase was detected in the liquid phase after $24 \mathrm{~h}$ of hydrolysis of lignocellulose with 6\% lignin (Tu et al., 2007a). These results suggest that the extent of non-productive adsorption of lignin is considerable despite the low lignin content in the substrate (Lu et al., 2002). Subsequently, after $90 \mathrm{~min}$ of readsorption, about $62.5 \%$ of the free protein in the solution was readsorbed onto the fresh corncob, close to the adsorption ratio observed during prehydrolysis $(\sim 60 \%)$. This result indicates that ethanol and the fermentation broth only slightly inhibit cellulase adsorption.

The distribution of cellulase components (CBH, EG, BGL) from prehydrolysis to re-adsorption was evaluated by SDS-PAGE analysis (Figure 4B). In previous studies, SDS-PAGE characterizations provided the molecular masses of single cellulases derived from $T$. reesei, that is, $67 \mathrm{kDa}$ for $\mathrm{CBHI}, 58 \mathrm{kDa}$ for CBHII, 48 $55 \mathrm{kDa}$ for EGI, and over $100 \mathrm{kDa}$ for $\beta$-glucosidase (Jäger et al., 2010). The SDS-PAGE gels in Figure 4B show that the concentrations of CBH I and CBH II, two major cellulase components, follow
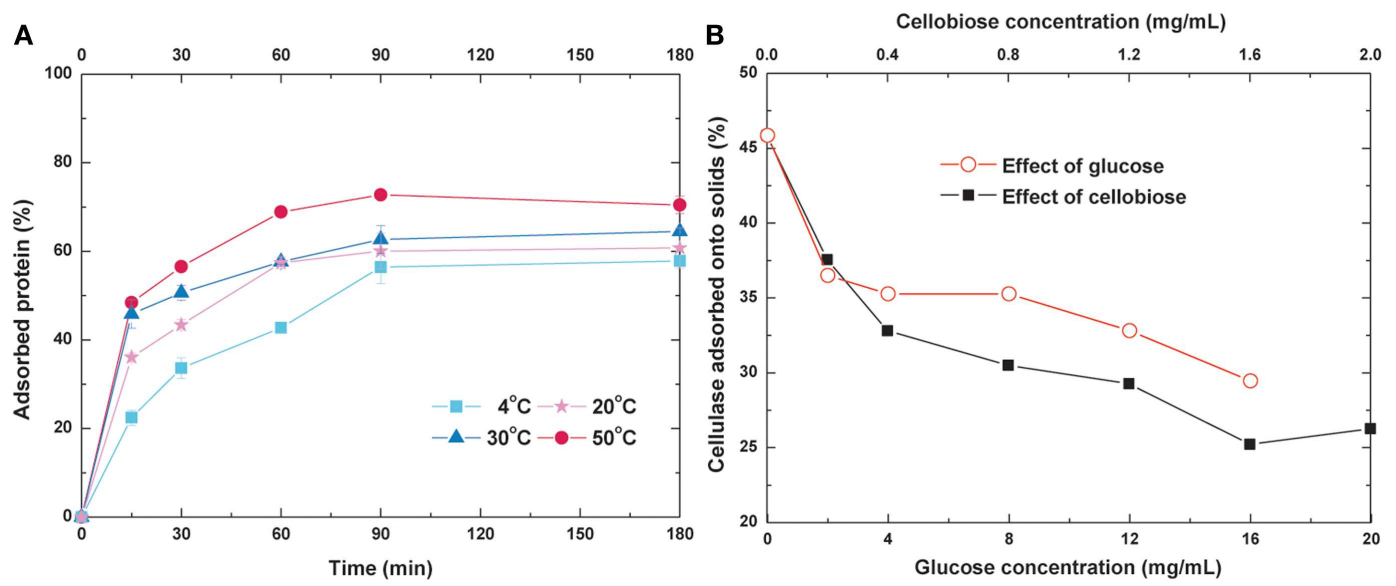

FIGURE 3 | Effects of (A) temperature and time and (B) glucose and cellobiose concentration on cellulase re-adsorption 
similar change rules according to the cellulase adsorption profile in Figure 4A. The band above $97 \mathrm{kDa}$ in the $\mathrm{P} 0$ column belongs to $\beta$-glucosidase (i.e., Novozyme 188). The intensity of this band
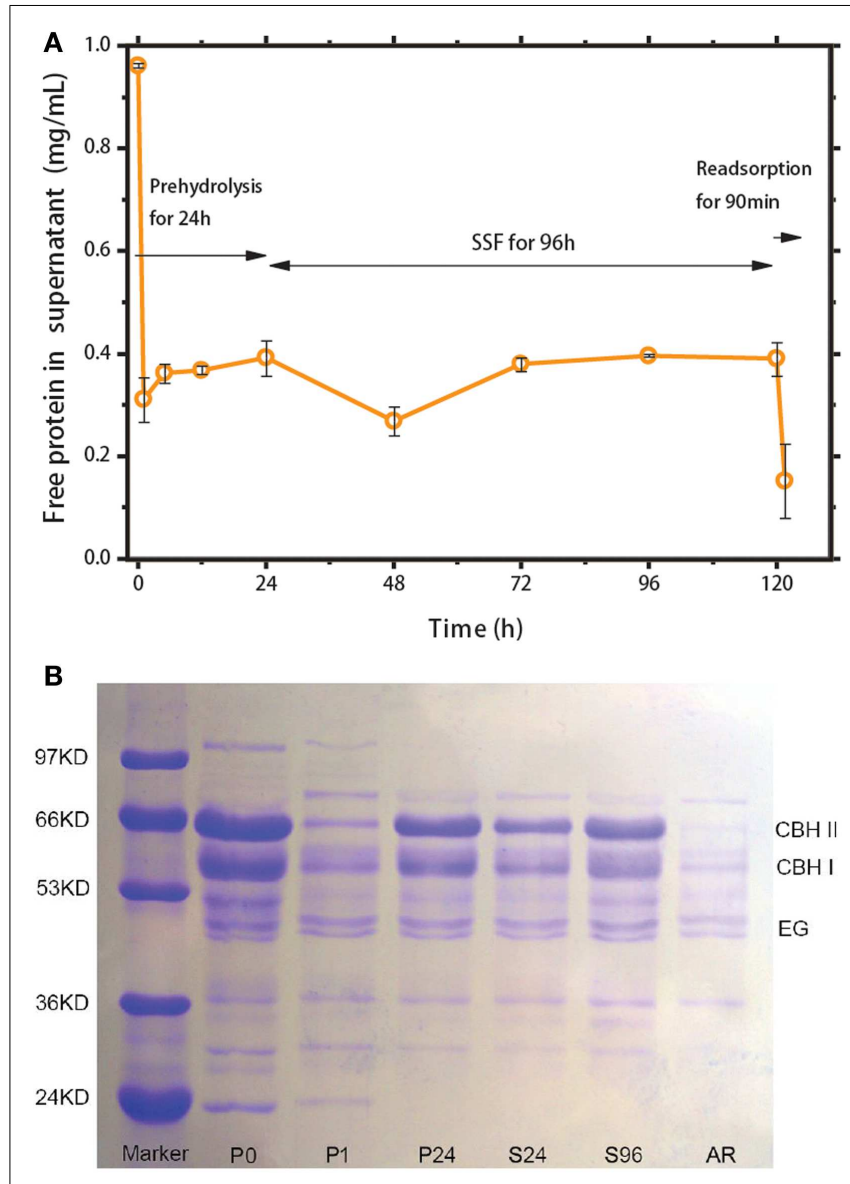

FIGURE 4 | (A) Tracking of cellulase adsorption during prehydrolysis, SSF, and re-adsorption. (B) SDS-PAGE analysis of cellulase in supernatant during prehydrolysis for 0 (P0), 1 (P1), and $24 \mathrm{~h}$ (P24); SSF for $24 \mathrm{~h}$ (S24) and $96 \mathrm{~h}$ (S96); and after re-adsorption (AR). decreased after the first $1 \mathrm{~h}$ of prehydrolysis and disappeared as the reaction proceeded, which deviates from the results reported previously (Tu et al., 2007a). Cellobiase (i.e., $\beta$-glucosidase) is a homogeneous catalyst without a cellulose-binding domain (CBD) and thus should have no ability to adsorb onto the cellulose substrate. However, in Figure 4B, the disappearance of this enzyme is most possibly brought about by physical adsorption onto the high-concentration substrate.

To optimize the operating conditions further, a single enzyme recycling run was performed according to Figure 1. The operating parameters for the SSF experiments may be found in Table 1. Three key factors were evaluated: enzyme loading, DM concentration, and $\mathrm{pH}$. Enzyme recycling combined with SSF was performed with three enzyme loadings (15, 30, and $45 \mathrm{FPU} / \mathrm{g}$ cellulose). For cellulose digestion, experimental data (Experiment Nos. 2, 4, and 6 ) in Table 3 show 14\% increase in cellulose conversion when the cellulase loading is increased from 15 to $30 \mathrm{FPU}$. However, further increases in loading ( $>30 \mathrm{FPU}$ ) cause no other changes to cellulose digestion, similar to previously reported results (Zhang et al., 2010a). Similar changes were also observed in terms of ethanol output because ethanol production is limited by the concentration of glucose produced from the CPC substrate. High cellulase loadings are more favorable for cellulase recycling because there will be more cellulase in the liquor for reuse. At a cellulase loading of under $45 \mathrm{FPU}$ (Experiment No. 6), the cellulose conversion and ethanol concentration obtained after the second cycle of SSF remained at $77.1 \%$ and $42.2 \mathrm{~g} / \mathrm{L}$, respectively, indicating a cellulase activity retention of $96.5 \%$.

Table 3 (Experiment Nos. 1, 4, and 7) showed the cellulose conversion and ethanol concentrations of two cycles of SSF with different DM concentrations. To obtain high concentrations of ethanol, all SSF cycles were operated with high-solid concentrations, which is, with DM of 12,15 , and $18 \%$, corresponding to cellulose concentrations of 93,116 , and $140 \mathrm{~g} / \mathrm{L}$, respectively. After the first cycle of SSF, the highest ethanol concentration was obtained at a DM concentration of $15 \%$. On the one hand, under a relatively low DM concentration (12\%), the ethanol concentration is limited by the lower fermentable glucose released from cellulose. On the other hand, under a relatively high DM

Table 3 | Summary of cellulose conversion rates, ethanol concentrations, and yields with different operating conditions for a single enzyme recycling run.

\begin{tabular}{|c|c|c|c|c|c|c|c|c|}
\hline No. & ${ }^{\mathrm{a}} \mathrm{CC}^{1 \text { st }}(\%)$ & ${ }^{b} E C^{1 s t}(g / L)$ & ${ }^{c} E Y^{1 s t}(\%)$ & $\mathrm{CC}^{2 \mathrm{nd}}(\%)$ & $E C^{2 n d}(g / L)$ & EY2nd (\%) & dAR (\%) & ePR (\%) \\
\hline 1 & 83.6 & $31.2 \pm 0.3$ & 71.0 & 59.3 & $24.2 \pm 0.4$ & 78.4 & 70.9 & 77.6 \\
\hline 2 & 66.6 & $28.6 \pm 0.6$ & 65.6 & 34.9 & $12.7 \pm 0.6$ & 56.0 & 52.4 & 44.4 \\
\hline 3 & 76.8 & $41.8 \pm 0.6$ & 83.8 & 57.0 & $27.5 \pm 0.5$ & 74.0 & 74.2 & 65.8 \\
\hline 4 & 80.5 & $42.2 \pm 1.5$ & 80.7 & 63.2 & $34.3 \pm 0.9$ & 83.2 & 78.5 & 81.2 \\
\hline 5 & 74.1 & $40.9 \pm 0.7$ & 85.0 & 60.8 & $33.3 \pm 0.6$ & 84.1 & 82.1 & 81.4 \\
\hline 6 & 79.9 & $41.7 \pm 0.8$ & 81.0 & 77.1 & $42.2 \pm 0.4$ & 83.8 & 96.5 & 101.2 \\
\hline 7 & 78.0 & $38.6 \pm 1.3$ & 63.5 & 48.8 & $36.5 \pm 0.8$ & 95.5 & 62.5 & 94.5 \\
\hline
\end{tabular}

${ }^{a} \mathrm{CC}$, cellulose conversion;

${ }^{b} E C$, ethanol concentration;

${ }^{c} E Y$, ethanol yield;

${ }^{d} A R$, activity recovery;

${ }^{e} P R$, productivity recovery. 
concentration (18\%), the ethanol concentration is limited by cellulose conversion because of insufficient mixing, high lignin content, and product inhibition (Kristensen et al., 2009b). At a DM concentration of $15 \%$ and enzyme loading of $30 \mathrm{FPU} / \mathrm{g}$ cellulose, the recovered cellulase shows good performance, resulting in a cellulose digestion of $63.2 \%$ after two cycles of SSF and a high ethanol concentration of $34.3 \mathrm{~g} / \mathrm{L}$, which corresponds to an ethanol yield of $83.2 \%$.

The optimal $\mathrm{pH}$ value for enzyme recycling combined with SSF was also investigated (Table 3, Experiment Nos. 3, 4, and 5). The highest cellulose conversion rates were observed at $\mathrm{pH} 5.0$ in two SSF cycles; these results demonstrate that $\mathrm{pH}$ factored exerts a majorly function on cellulose conversion instead of yeast performance. The optimal $\mathrm{pH}$ for cellulase activity is 4.8-5.0. At other $\mathrm{pH}$ values, the ability of cellulase significantly decreases, thereby reducing the concentration of fermentable sugars in the reactor. Table 3 shows that the ethanol concentrations of Experiment Nos. 4-9 in the second cycle of SSF were higher than $33 \mathrm{~g} / \mathrm{L}$. The resulting activity and productivity recoveries for different conditions also exceeded 62 and $78 \%$, respectively.

\section{EVALUATION OF EFFECTIVENESS OF ENZYME RECYCLING}

As shown in Table 3, higher cellulase recovery was achieved in Experiment Nos. 4 and 6 after one recycling run. To evaluate the digestion ability of the reabsorbed cellulase, enzyme recycling was carried out for several runs under the two conditions. Cellulose conversion and ethanol concentration were measured after each run. Using the recovered cellulase, the cellulose conversion and ethanol concentration reached $60 \%$ and $33 \mathrm{~g} / \mathrm{L}$, respectively, after one recycling run under the conditions applied in Experiment No. 4 (Figure 5A). Compared with the SSF results at lower cellulase loadings, cellulose conversion and ethanol concentrations were higher at a cellulase loading of $45 \mathrm{FPU} / \mathrm{g}$ cellulose because more free enzymes in the solution can be adsorbed to participate in the next reaction run. And the ethanol concentration obtained was fairly high at about $41.2 \mathrm{~g} / \mathrm{L}$, which is higher than $4 \%(\mathrm{v} / \mathrm{v})$ for economically viable lignocellulose-based ethanol processes (Wingren et al., 2003).

Hydrolysis yields and ethanol concentrations for both experiments decreased to $<35 \%$ and $20 \mathrm{~g} / \mathrm{L}$, respectively, after the second recycling run (Figure 5A). This result is probably due to the considerably low amount of free enzymes ( $<8 \%$ of the added cellulase at the beginning of SSF) remaining in the liquid phase. Here, the free enzyme amount was calculated according to the percentage of enzymes desorbed into the solution after $96 \mathrm{~h}$ of SSF multiplied by the re-adsorption ability for $90 \mathrm{~min}$. Reductions in hydrolysis efficiency during high-solids SSF may also explain this result (Kristensen et al., 2009a).

As shown in Figure 5B, when the enzyme was recycled for twice at a cellulase loading of $30 \mathrm{FPU} / \mathrm{g}$ cellulose, total cellulose digestion and total produced ethanol in the reactor increased to 195.7 and $75.1 \mathrm{~g} / \mathrm{L}$, corresponding 2.1 - and 1.8 -fold those in single round at the same loading of cellulase, respectively. At a cellulase loading of $45 \mathrm{FPU} / \mathrm{g}$ cellulose, $227.5 \mathrm{~g} / \mathrm{L}$ cellulose was degraded and $101.1 \mathrm{~g} / \mathrm{L}$ ethanol was obtained. Nevertheless, the higher cellulase loadings prevented the use of more enzymes in the reaction. As seen in Figure 5B, the unit productivity of ethanol, which refers

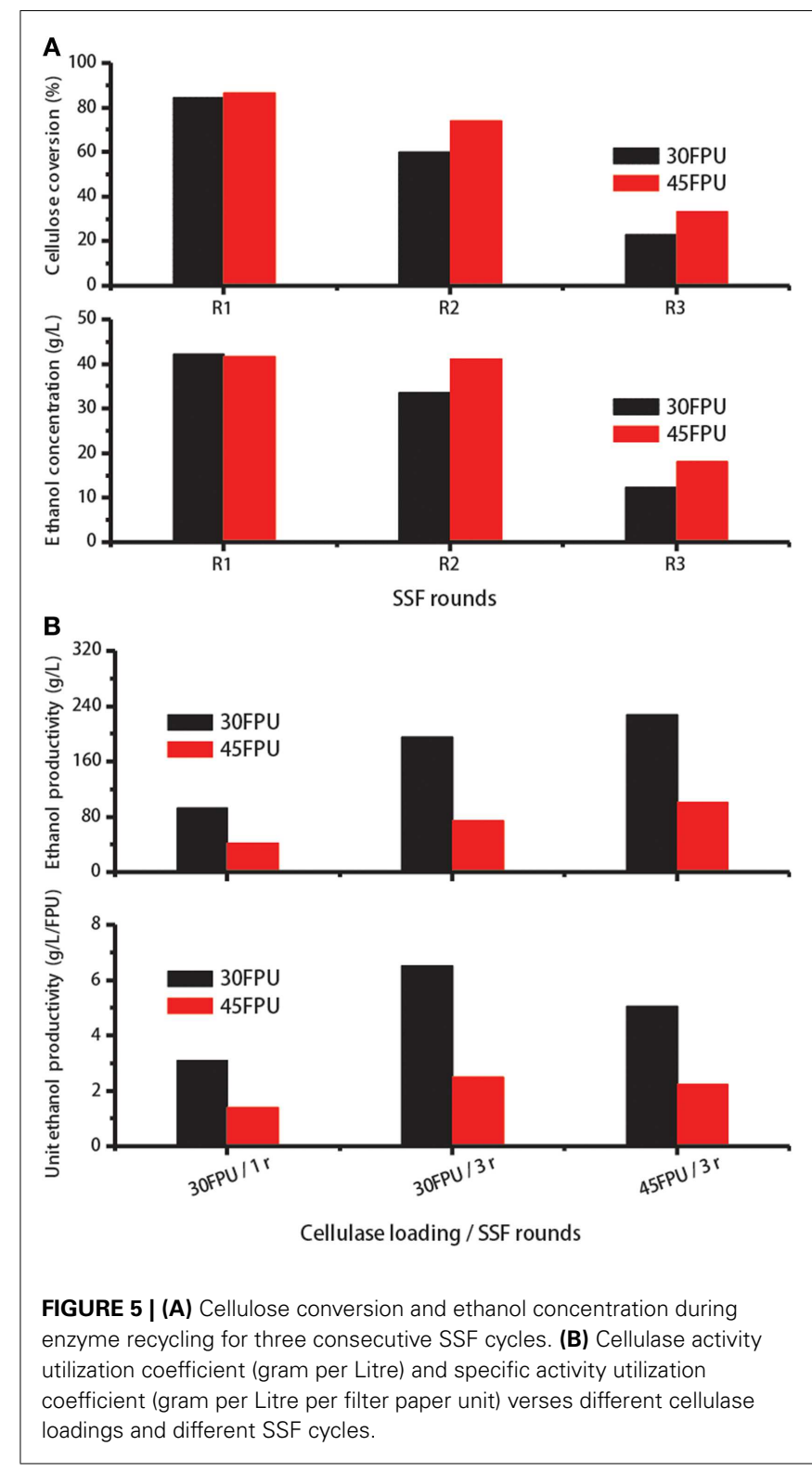

to the utilization coefficient of cellulase, was higher relatively at a cellulase loading of 30 FPU. Although the enzymes were not fully utilized in the first round cycle of SSF at 45 FPU loading, operating under this condition benefited the subsequent enzyme recycling. The ethanol concentration obtained after two consecutive cycles of SSF rounds both exceeded 4\%. Based on these results, two-cycle SSF combined with re-adsorption can be performed at a cellulase loading of $45 \mathrm{FPU}$, which can reduce enzyme costs by at least half.

\section{CONCLUSION}

In summary, we have developed an integrated strategy, incorporating cellulase recycling and high-solids SSF, to enhance enzyme utilization and final ethanol concentration. After SSF, $40 \%$ of the initial cellulase was remained in the suspension. Approximately $62.5 \%$ of the free cellulase protein could be recovered under the 
conditions (pH 5.0; DM 15\%). Under the conditions, i.e., $\mathrm{pH}$ 5.0, dry matter loading of $15 \mathrm{wt} \%$, cellulase loading of $45 \mathrm{FPU} / \mathrm{g}$ glucan, two cycles of fermentation and re-adsorption can yield twofold increased ethanol outputs and reduce enzyme costs by over $50 \%$. The ethanol concentration in each cycle can be achieved at levels $>40 \mathrm{~g} / \mathrm{L}$.

\section{ACKNOWLEDGMENTS}

The authors acknowledge the financial supports received from the National Natural Science Foundation of China (Nos. 21276192 and 20976125), Open Funding Project of the State Key Laboratory of Chemical Engineering (No. SKL-ChE-11B01), and the Ministry of Education (Nos. NCET-11-0372, 20110032130004, and B06006).

\section{REFERENCES}

Andric, P., Meyer, A. S., Jensen, P. A., and Dam-Johansen, K. (2010). Effect and modeling of glucose inhibition and in situ glucose removal during enzymatic hydrolysis of pretreated wheat straw. Appl. Biochem. Biotechnol. 160, 280-297. doi:10.1007/s12010-008-8512-9

Bansal, P., Hall, M., Realff, M. J., Lee, J. H., and Bommarius, A. S. (2009). Modeling cellulase kinetics on lignocellulosic substrates. Biotechnol. Adv. 27, 833-848. doi:10.1016/j.biotechadv.2009.06.005

Berlin, A., Gilkes, N., Kurabi, A., Bura, R., Tu, M., Kilburn, D., et al. (2005). Weak lignin-binding enzymes - a novel approach to improve activity of cellulases for hydrolysis of lignocellulosics. Appl. Biochem. Biotechnol. 121, 163-170. doi:10.1385/abab:121:1-3:0163

Bradford, M. M. (1976). A rapid and sensitive method for the quantitation of microgram quantities of protein utilizing the principle of protein-dye binding. Anal. Biochem. 72, 248-254. doi:10.1016/0003-2697(76)90527-3

Du, R., Huang, R., Su, R., Zhang, M., Wang, M., Yang, J., et al. (2013). Enzymatic hydrolysis of lignocellulose: SEC-MALLS analysis and reaction mechanism. RSC Adv. 3, 1871-1877. doi:10.1039/c2ra21781c

Du, R., Su, R., Li, X., Tantai, X., Liu, Z., Yang, J., et al. (2012). Controlled adsorption of cellulase onto pretreated corncob by $\mathrm{pH}$ adjustment. Cellulose 19, 371-380. doi:10.1007/s10570-012-9653-0

Georgieva, T. I., Hou, X., Hilstrøm, T., and Ahring, B. K. (2008). Enzymatic hydrolysis and ethanol fermentation of high dry matter wet-exploded wheat straw at low enzyme loading. Appl. Biochem. Biotechnol. 148, 35-44. doi:10.1007/s12010007-8085-z

Ghose, T. K. (1987). Measurement of cellulase activities. Pure Appl. Chem. 59, 257-268. doi:10.1351/pac198759020257

Huang, R., Qi, W., Su, R., and He, Z. (2010a). The optimization of fractionating lignocellulose by formic acid using response surface methodology. Energy Sources Part A 32, 1282-1292. doi:10.1080/15567030903076669

Huang, R., Su, R., Qi, W., and He, Z. (2010b). Understanding the key factors for enzymatic conversion of pretreated lignocellulose by partial least square analysis. Biotechnol. Prog. 26, 384-392. doi:10.1002/btpr.324

Huang, R., Su, R., Qi, W., and He, Z. (2011). Bioconversion of lignocellulose into bioethanol: process intensification and mechanism research. Bioenergy Res. 4, 225-245. doi:10.1007/s12155-011-9125-7

Jäger, G., Wu, Z., Garschhammer, K., Engel, P., Klement, T., Rinaldi, R., et al. (2010). Practical screening of purified cellobiohydrolases and endoglucanases with alpha-cellulose and specification of hydrodynamics. Biotechnol. Biofuels 3, 18. doi:10.1186/1754-6834-3-18

Jørgensen, H., Vibe-Pedersen, J., Larsen, J., and Felby, C. (2007). Liquefaction of lignocellulose at high-solids concentrations. Biotechnol. Bioeng. 96, 862-870. doi:10.1002/bit.21115

Kristensen, J. B., Felby, C., and Jørgensen, H. (2009a). Determining yields in high solids enzymatic hydrolysis of biomass. Appl. Biochem. Biotechnol. 156, 127-132. doi:10.1007/s12010-008-8375-0

Kristensen, J. B., Felby, C., and Jørgensen, H. (2009b). Yield-determining factors in high-solids enzymatic hydrolysis of lignocellulose. Biotechnol. Biofuels 2, 11. doi:10.1186/1754-6834-2-11

Laemmli, U. K. (1970). Cleavage of structural proteins during the assembly of the head of bacteriophage T4. Nature 227, 680-685. doi:10.1038/227680a0
Li, H., Kim, N.-J., Jiang, M., Kang, J. W., and Chang, H. N. (2009). Simultaneous saccharification and fermentation of lignocellulosic residues pretreated with phosphoric acid-acetone for bioethanol production. Bioresour. Technol. 100, 3245-3251. doi:10.1016/j.biortech.2009.01.021

Liu, K., Lin, X., Yue, J., Li, X., Fang, X., Zhu, M., et al. (2010). High concentration ethanol production from corncob residues by fed-batch strategy. Bioresour. Technol. 101, 4952-4958. doi:10.1016/j.biortech.2009.11.013

Lu, Y., Yang, B., Gregg, D., Saddler, J. N., and Mansfield, S. D. (2002). Cellulase adsorption and an evaluation of enzyme recycle during hydrolysis of steam-exploded softwood residues. Appl. Biochem. Biotechnol. 98-100, 641-654. doi:10.1385/abab:98-100:1-9:641

Lynd, L. R., Weimer, P. J., Zyl, W. H. V., and Pretorius, I. S. (2002). Microbial cellulose utilization: fundamentals and biotechnology. Microbiol. Mol. Biol. Rev. 66, 506-577. doi:10.1128/mmbr.66.3.506-577.2002

Qi, B., Chen, X., Su, Y., and Wan, Y. (2011). Enzyme adsorption and recycling during hydrolysis of wheat straw lignocellulose. Bioresour. Technol. 102, 2881-2889. doi:10.1016/j.biortech.2010.10.092

Qi, B., Luo, J., Chen, G., Chen, X., and Wan, Y. (2012). Application of ultrafiltration and nanofiltration for recycling cellulase and concentrating glucose from enzymatic hydrolyzate of steam exploded wheat straw. Bioresour. Technol. 104, 466-472. doi:10.1016/j.biortech.2011.10.049

Tomás-Pejó, E., Oliva, J. M., Ballesteros, M., and Olsson, L. (2008). Comparison of SHF and SSF processes from steam-exploded wheat straw for ethanol production by xylose-fermenting and robust glucose-fermenting Saccharomyces cerevisiae strains. Biotechnol. Bioeng. 100, 1122-1131. doi:10.1002/bit.21849

Tu, M., Chandra, R. P., and Saddler, J. N. (2007a). Evaluating the distribution of cellulases and the recycling of free cellulases during the hydrolysis of lignocellulosic substrates. Biotechnol. Prog. 23, 398-406. doi:10.1021/bp060354f

Tu, M., Chandra, R. P., and Saddler, J. N. (2007b). Recycling cellulases during the hydrolysis of steam exploded and ethanol pretreated lodgepole pine. Biotechnol. Prog. 23, 1130-1137. doi:10.1021/bp070129d

Tu, M., and Saddler, J. N. (2010). Potential enzyme cost reduction with the addition of surfactant during the hydrolysis of pretreated softwood. Appl. Biochem. Biotechnol. 161, 274-287. doi:10.1007/s12010-009-8869-4

Tu, M., Zhang, X., Kurabi, A., Gilkes, N., Mabee, W., and Saddler, J. (2006). Immobilization of $\beta$-glucosidase on Eupergit $\mathrm{C}$ for lignocellulose hydrolysis. Biotechnol. Lett. 28, 151-156. doi:10.1007/s10529-005-5328-3

Tu, M., Zhang, X., Paice, M., Macfarlane, P., and Saddler, J. N. (2009). The potential of enzyme recycling during the hydrolysis of a mixed softwood feedstock. Bioresour. Technol. 100, 6407-6415. doi:10.1016/j.biortech.2009.06.108

Varga, E., Klinke, H. B., Réczey, K., and Thomsen, A. B. (2004). High solid simultaneous saccharification and fermentation of wet oxidized corn stover to ethanol. Biotechnol. Bioeng. 88, 567-574. doi:10.1002/bit.20222

Wang, G. S., Lee, J.-W., Zhu, J. Y., and Jeffries, T. W. (2011). Dilute acid pretreatment of corncob for efficient sugar production. Appl. Biochem. Biotechnol. 163, 658-668. doi:10.1007/s12010-010-9071-4

Wang, P., Hu, X., Cook, S., and Hwang, H.-M. (2009). Influence of silica-derived nano-supporters on cellobiase after immobilization. Appl. Biochem. Biotechnol. 158, 88-96. doi:10.1007/s12010-008-8321-1

Wingren, A., Galbe, M., and Zacchi, G. (2003). Techno-economic evaluation of producing ethanol from softwood: comparison of SSF and SHF and identification of bottlenecks. Biotechnol. Prog. 19, 1109-1117. doi:10.1021/bp0340180

Zhang, M., Su, R., Qi, W., and He, Z. (2009). Enzymatic conversion of lignocellulose into sugars. Prog. Chem. 21, 1070-1074.

Zhang, M., Su, R., Qi, W., and He, Z. (2010a). Enhanced enzymatic hydrolysis of lignocellulose by optimizing enzyme complexes. Appl. Biochem. Biotechnol. 160, 1407-1414. doi:10.1007/s12010-009-8602-3

Zhang, M., Wang, F., Su, R., Qi, W., and He, Z. (2010b). Ethanol production from high dry matter corncob using fed-batch simultaneous saccharification and fermentation after combined pretreatment. Bioresour. Technol. 101, 4959-4964. doi:10.1016/j.biortech.2009.11.010

Zheng, Y., Pan, Z., Zhang, R., and Jenkins, B. M. (2009). Kinetic modeling for enzymatic hydrolysis of pretreated creeping wild ryegrass. Biotechnol. Bioeng. 102, 1558-1569. doi:10.1002/bit.22197

Conflict of Interest Statement: The authors declare that the research was conducted in the absence of any commercial or financial relationships that could be construed as a potential conflict of interest. 
Received: 14 April 2014; paper pending published: 15 May 2014; accepted: 11 June 2014; published online: 26 June 2014.

Citation: Du R, Su R, Zhang M, Qi W and He Z (2014) Cellulase recycling after highsolids simultaneous saccharification and fermentation of combined pretreated corncob. Front. Energy Res. 2:24. doi: 10.3389/fenrg.2014.00024

This article was submitted to Bioenergy and Biofuels, a section of the journal Frontiers in Energy Research.
Copyright (C) $2014 \mathrm{Du}, \mathrm{Su}, \mathrm{Zhang}, \mathrm{Qi}$ and He. This is an open-access article distributed under the terms of the Creative Commons Attribution License (CC BY). The use, distribution or reproduction in other forums is permitted, provided the original author(s) or licensor are credited and that the original publication in this journal is cited, in accordance with accepted academic practice. No use, distribution or reproduction is permitted which does not comply with these terms. 